\title{
Los outsiders de la política uruguaya: abordaje desde la semiótica ${ }^{1}$
}

\section{The Outsiders of Uruguayan Politics: approach from semiotics}

\author{
Sebastián Moreno Barreneche ${ }^{2}$
}

\section{Resumen}

Este artículo estudia desde una perspectiva semiótica la reciente aparición en el escenario político uruguayo de candidatos outsiders. Concretamente, se trabaja sobre la base de cuatro figuras, tres de las cuales cobraron notoriedad en el marco de las elecciones nacionales de 2019: Ernesto Talvi, Juan Sartori y Guido Manini Ríos. Para complementar el análisis, se estudia también la figura de Edgardo Novick, cuyo ingreso a la política, que data de 2015, constituye también un interesante caso de outsider. El artículo discute cómo los cuatro candidatos construyeron su posicionamiento dentro del escenario político uruguayo a partir de las categorías «el académico», «el empresario», «el militar»y «el laburante», respectivamente, todas vinculadas con su actividad previa a la incursión en política.

Palabras clave: Outsiders; Uruguay; semiótica; discurso; política

\begin{abstract}
This article studies from a semiotic perspective the recent irruption of outsider candidates in the Uruguayan political scene. Specifically, it focuses in four candidates. Three of them gained visibility within the framework of the 2019 Uruguayan national elections - these are Ernesto Talvi, Juan Sartori and Guido Manini Ríos. In addition, the article also includes an analysis of Edgardo Novick, a fourth candidate that joined politics in 2015 as an outsider. The article discusses how these four candidates constructed their positioning within the Uruguayan political scene through the categories of «the academic», «the businessman», «the military soldier» and «the hard-worker», respectively, all of them based on their professional activities prior to joining politics.
\end{abstract}

Keywords: Outsiders; Uruguay; semiotics; discourse; politics

1 Trabajo recibido el 31/03/2021. Aceptado el 11/06/2021.

${ }^{2}$ Universidad ORT (Uruguay). Contacto: morenobarreneche@gmail.com 


\section{Introducción}

En años recientes, la tradicional partidocracia uruguaya -un sistema que, en términos históricos, muy pocas veces ha develado sorpresas durante los ciclos electorales- se vio sorprendida por una irrupción (hasta cierto punto inesperada) de candidatos provenientes de ámbitos profesionales externos a la política. Mientras que algunos de estos candidatos optaron por asociarse a los partidos del país que, por su historia y relevancia electoral, pueden considerarse clásicos (Partido Colorado, Partido Nacional y Frente Amplio), otros irrumpieron en la escena política a través de la creación y/o mediante una asociación con partidos de origen reciente (Partido de la Gente y Cabildo Abierto).

En las elecciones internas de junio de $2019,{ }^{3}$ tres nuevas figuras irrumpieron en el escenario político uruguayo en calidad de candidatos presidenciales: se trata de Ernesto Talvi (por el Partido Colorado), Juan Sartori (por el Partido Nacional) y Guido Manini Ríos (por Cabildo Abierto). A estas tres figuras se suma la de Edgardo Novick (representante del Partido de la Gente), un empresario cuya irrupción en la política nacional data de mediados de la década del 2010. Además de la novedad de sus candidaturas en el tradicional y partidocrático contexto nacional, los sorprendentes resultados electorales de los tres primeros candidatos en las elecciones internas de 2019, así como las del último en las departamentales de 2015, ameritan una reflexión minuciosa sobre este fenómeno, que parecería estar reflejando ciertas tendencias en el ámbito político que, hasta hace poco tiempo, parecían no haber afectado al Uruguay, como ser el desgaste de los partidos políticos o la desconfianza ciudadana en las instituciones tradicionales (Cerna Villagra, 2012).

En un artículo reciente, Federico Musto Crucci (2020) propone un interesante estudio politológico de los tres primeros candidatos como outsiders y sostiene que «la aparición de figuras que se insertan en la política partidaria desde afuera del sistema (algunos dentro de partidos consolidados y otros creando nuevos partidos) invita a analizar con mayor detenimiento el fenómeno con una perspectiva politológica» (p. 225). Este artículo intenta contribuir a dicho análisis desde una perspectiva semiótica, esto es, interesada por comprender cómo el sentido y la signi-

\footnotetext{
${ }^{3}$ En Uruguay, las elecciones internas son aquellas en las que el electorado vota por un candidato dentro de su partido de preferencia, para que este sea el representante único del partido en las elecciones nacionales de octubre.
} 
ficación circulan en la sociedad (Fabbri, 1998; Landowski, 2014; Verón, 1988). Concretamente, en estas páginas se examinarán los roles narrativos mediante los cuales estos cuatro candidatos -E. Talvi, J. Sartori, G. Manini Ríos y E. Novick- se posicionaron en la esfera política uruguaya. Si, como proponía Eliseo Verón (1989), la semiótica aspira a lograr una «reconstrucción de la producción del sentido en el seno de las redes interdiscursivas de nuestras sociedades» (p. 138), un análisis de esta naturaleza resulta entonces fundamental para comprender las lógicas y dinámicas de producción de sentido subyacentes al quehacer político, tanto de manera general como en el caso de una sociedad dada. Al llevar a cabo dicho análisis, quedará en evidencia la articulación narrativa de la esfera pública.

Para lograr el objetivo planteado, la primera sección del artículo presenta algunas consideraciones generales sobre qué implica abordar la esfera política de una sociedad desde una perspectiva semiótica. Como se argumenta, la esfera pública debe ser concebida como una semiosfera articulada en la forma de un campo discursivo dentro del cual la producción y circulación de sentido son posibles. Luego, la segunda sección se detiene en estudiar la figura del outsider. Finalmente, en la tercera y última sección se presenta el análisis de los cuatro outsiders seleccionados. La hipótesis subyacente a lo que sigue es que cada uno de estos candidatos ingresó a la esfera política uruguaya sujetándose a un rol narrativo específico, asociado a su experiencia profesional previa, lo que facilitó su posicionamiento dentro del complejo entramado de significados y sentido que representa cualquier esfera pública.

\section{La esfera política como campo de producción de sentido}

Cristina Peñamarín (2020) define a la esfera pública de una sociedad como «un espacio de mediación comunicativa entre representantes políticos y ciudadanía» en el que el segundo grupo puede «formarse una opinión sobre los asuntos públicos e informarse sobre las actuaciones de los responsables políticos» (p. 62). Según esta definición, la esfera pública tendría un inescapable carácter discursivo, como Eliseo Verón propuso en sus trabajos sobre el campo político, al que concibió como un campo discursivo adversativo, construido a partir del intercambio de discursos enunciados por actores políticos y dirigidos a distintos colectivos (Verón, 1987; 1998). La esfera pública sería entonces un espacio de co- 
municación entre actores sociales, en el que la atribución de sentido juega un rol esencial.

Un enfoque constructivista como el de la semiótica se interesará por la esfera pública no como un fenómeno estático y dado, sino como uno construido e in vivo, esto es, en su hacerse permanente, en las múltiples interacciones que en él se desarrollan (Landowski, 2014; Moreno Barreneche, 2020a). Para Peñamarín (2020), la esfera pública, «hoy más compleja y enredada que nunca, surge (...) de la selección, definición y tratamiento, por parte de diferentes actores y medios, de cierto número de asuntos convertidos en objetos de atención pública» (p. 62). En otras palabras: la esfera pública es construida a partir del interés en ciertos temas por parte de actores sociales, por lo que esta ha sido por lo general abordada «a partir del estudio de la construcción de asuntos o problemas públicos, su proceso de definición, discusión, publicitación, resolución, como un proceso que construye, al tiempo que un asunto público, la propia esfera pública» (p. 62). En este sentido, al estudiar la esfera pública desde una perspectiva semiótica, se deberá realizar un recorte de aquella porción que sea de interés para el investigador, focalizándose en un tema (o un conjunto de temas) de los tantos que en ella existen, para detectar cómo es que el sentido se manifiesta y, más precisamente, se construye, a partir de las múltiples intervenciones de actores políticos.

A pesar de la centralidad que los temas tienen en la esfera pública, esta es mucho más compleja y trasciende los contenidos específicos que se debaten en una sociedad dada. A modo de ejemplo, Peñamarín destaca la importancia de la dimensión afectiva. Para Grigoris Paschalidis (2020), por su parte, un estudio semiótico de la cosa política debe atender a un espectro altamente diverso de textos, artefactos, rituales, prácticas y medios. Si bien para la semiótica será fundamental estudiar qué se dice en la esfera política (así como quién y cómo lo enuncia), otros aspectos deberán ser considerados, aunque a simple vista estos parezcan de una naturaleza menos discursiva que los contenidos temáticos.

Un punto de sumo interés para la semiótica social más allá de lo temático pasa por los actores que forman parte de la esfera política de una sociedad dada. Estos, que también son resultado de ciertas estrategias discursivas (Moreno Barreneche 2020b; Verón, 1987), pueden ser colectivos, como en el caso de partidos políticos, sindicatos, instituciones gubernamentales, colectivos, etc. o individuales. Respecto al primer caso, en un artículo reciente (Moreno Barreneche 2020b) intenté defender un enfoque semiótico-discursivo sobre cómo concebir la construcción de las 
identidades políticas colectivas a partir de una inescapable brecha, dado que toda identidad se construye a partir de la diferencia, como se ha señalado desde los estudios del discurso (Arfuch, 2005; Laclau, 2005; Mouffe, 2007).

En el caso de actores políticos individuales, como ser un candidato presidenciable, tal construcción discursiva resulta menos evidente y problemática, ya que en el caso de individuos la identidad no se asocia a un «nosotros» que debe ser construido y delimitado en y por el discurso (a partir de una postulación de ciertas propiedades comunes vinculantes y de un distanciamiento de un «otro» imaginado), sino que pasa por lo personal. Dada la inevitable encarnación de todo sujeto, la identidad personal tiene siempre un fuerte anclaje en el cuerpo, así como a un conjunto de datos personales, como ser un nombre propio, una narrativa (auto)biográfica, etc., lo cual facilita la percepción del yo de manera diferencial.

Sin embargo, la presencia de actores políticos individuales en la esfera pública no está liberada de cuestiones discursivas que son de sumo interés para la semiótica. A mediados del siglo XX, Erving Goffman (1959) sostenía que «cuando un individuo comparece ante otros, por lo general habrá alguna razón para que desenvuelva su actividad de modo tal que transmita a los otros una impresión que a él le interesa transmitir» (p. 18). Es decir, habrá una gestión estratégica del yo que se manifestará en determinados actos de enunciación orientados a producir sentido en los otros participantes de la interacción. En la época actual, tal comparecencia no se limita únicamente a encuentros cara a cara, sino que se desarrolla también de manera mediada, tanto en medios masivos tradicionales como en los online. Así, los individuos que participan en la esfera pública disponen de un amplio abanico de espacios, plataformas y recursos semióticos para proyectar y construir su identidad personal.

En el campo político, todo actor individual tendrá interés en gestionar de manera estratégica las impresiones que produce ante los participantes de dicha esfera, un proceso de naturaleza semiótica -de producción de conjuntos significantes autorreferenciales que implican una enunciación y una manipulación de recursos semióticos- para el que existen diversos caminos posibles. Uno de ellos, a modo de ejemplo, se relaciona con la tensión existente entre el yo público y el yo privado. Cuestiones como estas dejan en evidencia que la gestión de la imagen personal que es proyectada será fundamental a la hora de participar en la esfera pública, sea oralmente (mediante discursos, apariciones en medios de comu- 
nicación, etc.), a través de la creación de contenidos en redes sociales (tweets, discursos escritos, etc.) o a través de los contenidos creados por los medios de comunicación.

En síntesis: si bien en el caso de los actores políticos individuales se requiere menos esfuerzo semiótico para construir la identidad del actor (en comparación al caso de las identidades colectivas), también hay un trabajo de manipulación de recursos semióticos para proyectar determinada imagen. Los consultores en comunicación que Verón (1994) señalaba en la década de 1990 operan precisamente en este campo: como propone el semiotista, el campo político es «un área discursiva que constituye el lugar de encuentro de una gran variedad de operadores estratégicos» (Verón, 1998, p. 224).

En términos semióticos, toda esfera pública puede ser concebida como una semiosfera (Lotman, 1996), esto es, como un espacio con ciertos límites más allá de los cuales la circulación de sentido de manera inteligible no es posible. Este carácter de espacio delimitado queda en evidencia, a modo de ejemplo, cuando un extranjero intenta familiarizarse con los contenidos y actores políticos de un país que desconoce: harán falta tiempo y contacto con los contenidos de los medios masivos de comunicación, conversaciones cotidianas, redes sociales, etc. para sumergirse en ese espacio de sentido, amueblado con personajes, temas, instituciones, prácticas y formas de interacción específicas. ${ }^{4}$ Por el contrario, para un individuo familiarizado con la esfera pública, será muy sencillo identificar y reconocer a los partidos, actores, temas, prácticas y procedimientos que hacen a lo político en un contexto dado.

Dentro de la semiosfera, cada uno de estos elementos está posicionado $^{5}$ de manera relacional, esto es, como una unidad de sentido incrustado en una malla de unidades con significado que permiten que lo que allí sucede tenga sentido (Hjelmslev, 1943; Eco, 1976). Partidos políticos, gobernantes, candidatos y otros actores despertarán en los observadores asociaciones que permitirán su posicionamiento en esa compleja malla de significados que constituye el campo discursivo de lo político. En otras palabras: además de sí mismos en cuanto que personas, los actores políticos individuales deberán construir su espacio dife-

\footnotetext{
${ }^{4}$ A modo de ejemplo, se puede pensar en la sorpresa que suelen generar las interacciones en el Parlamento británico para cualquier observador no familiarizado con la política del Reino Unido.

${ }^{5}$ Las metáforas espaciales, por vagas e imprecisas que parezcan, son utilizadas por Lotman en su caracterización de la semiosfera.
} 
rencial dentro de esa malla de significados. Por lo tanto, cuando nuevos actores políticos irrumpen en la esfera pública, estos no solo deberán presentarse mediante el uso de su cuerpo y otros recursos de carácter personal (nombre, estilo propio, biografía, etc.), sino que, además, deberán construir su 'casillero' en ese entramado significante, de modo tal que el sistema se ajuste para ubicarlos dentro de la configuración de sentido.

Este fenómeno va de la mano con una de las premisas básicas de la semiótica contemporánea (particularmente, de su variante cognitiva): la percepción se configura de manera narrativa (Paolucci, 2012; 2021). En términos políticos, esto se traduce en que, dentro de una sociedad, la cosa política será percibida y dotada de sentido a través de la mediación de historias en las que los actores ocuparán roles específicos, como los del héroe, el villano, etc. ${ }^{6}$ Tal construcción narrativa dependerá, evidentemente, de la mediación de una valorización ideológica de la política local: mientras que para algunos participantes un determinado «nosotros» (por ejemplo, un partido político dado) puede ser el héroe que lucha por mejorar la situación del país, para otros ese colectivo puede ser el «ellos» enemigo que se presenta como obstáculo para alcanzar dicho fin. ${ }^{7} \mathrm{Si}$ la percepción se configura de manera narrativa, entonces la irrupción de nuevos actores políticos -los llamados outsiders que interesan en este artículo- implicará dotar a esos individuos de significado y sentido, esto es, de referencias (descripciones, connotaciones, etc.) que permitan ubicarlos en la trama de lo político a través de su construcción actorial en cuanto que participantes de historias que persiguen ciertos objetivos (en términos semióticos, estos actores tienen un programa narrativo en el que intentan alcanzar un estado de conjunción con el objeto de valor que, discursivamente, proponen como su meta).

\section{La figura del outsider en política}

El fenómeno de los outsiders en política no representa ninguna novedad a nivel global, aunque recientemente ha sido de especial interés

\footnotetext{
${ }^{6}$ A modo de ejemplo, María Esperanza Casullo (2019) estudia el discurso populista a partir de estos roles.

7 Esta es la lógica subyacente a los fenómenos de polarización afectiva y de fanatismo «blando» (Moreno Barreneche, 2020c; 2020d), tan frecuentes en nuestros días.
} 
en el marco de las investigaciones sobre el populismo (Barr, 2009). Tampoco representa una novedad a nivel latinoamericano, ya que, en décadas pasadas, personajes como Alberto Fujimori, Hugo Chávez y Rafael Correa -todos ellos outsiders- llegaron a ser presidentes de Perú, Venezuela y Ecuador, respectivamente (Carreras, 2013). Sin embargo, en Uruguay sí constituye un caso novedoso, ya que, a lo largo de las décadas posteriores a la dictadura militar (1973-1985), los personajes de la política han seguido una lógica bastante constante de ingreso a y permanencia en la esfera pública (a modo de ejemplo, entre 1985 y 2021, tanto Julio María Sanguinetti como Tabaré Vázquez fueron reelectos como presidentes).

La característica definitoria del rol del outsider está ya contenida en el sustantivo que le da nombre. En línea con la conceptualización que Lotman realizó de la semiosfera, esta característica es de carácter espacial: como señala Roberto Rodríguez Andrés (2016), el outsider es quien viene «de afuera», esto es, «aquella persona que no pertenece a un determinado grupo, comunidad, organización o profesión o está excluida de la misma» (p. 75). Un outsider es, por lo tanto, alguien que proviene del «más allá», esto es, de fuera de los límites imaginados para un campo de acción social determinado.

Así como en todo grupo social un recién llegado debe presentarse ante los demás, el caso de la política no es la excepción: será fundamental no solo atender a la procedencia del outsider (cómo es tematizada, si se la destaca o la oculta, qué valor se le otorga, cómo esta justifica la incursión en política), sino también a cómo es que se posiciona dentro de la esfera pública (esto es, qué rol pretende ocupar en la trama narrativa de la cosa política, qué asociaciones y connotaciones intenta promover en relación a sí mismo, de qué temas se ocupará, etc.). Si, como propone Musto Crucci (2020), «cuando una persona decide insertarse en la arena política queda instalado de manera inmediata en la esfera mediática» (p. 229), la circulación de sentido en torno a ella será inevitable.

En términos conceptuales, en el campo de la política se puede hablar de outsiders para referir a distintos fenómenos, todos ellos atravesados por el hecho de que el candidato en cuestión no tiene experiencia previa en política. Para Rodríguez Andrés (2016), son tres los casos abarcados por este concepto. En primer lugar, los candidatos que, provenientes de otros campos de lo social y sin tener experiencia previa en política, se presentan a elecciones (como veremos en la próxima sección, este es el caso de los cuatro candidatos estudiados en estas páginas). En segundo lugar, están los políticos que se ubican «al margen de las convencio- 
nes tradicionales de la política o se muestran contrarios a las mismas, presentándose como una alternativa o una visión crítica a lo esta-blecido» (p. 76). Finalmente, el término puede ser utilizado para referir a quienes, «teniendo todo en contra y muy pocas aspiraciones de triunfo en unas elecciones, logran alzarse al final con la victoria» (p. 76).

Por su parte, Miguel Carreras (2013) identifica dos dimensiones macro como aquellas que definen a un candidato outsider: por un lado, las características de su relación con los partidos políticos, que, por lo general, es una de distancia; por el otro, la carrera política previa del candidato. A su vez, el autor agrega que «el concepto de outsider tiene dos dimensiones constitutivas: 1) inexperiencia política y 2) búsqueda del poder a través de un partido nuevo» (p. 98), a las que identifica como necesarias para que un candidato pueda ser considerado outsider. Veremos en la próxima sección cómo el caso uruguayo supone un reto para estas dos condiciones, específicamente la segunda, ya que dos de los cuatro candidatos aquí estudiados optaron por afiliarse a partidos ya existentes (aunque hayan creado sectores nuevos dentro de ellos).

Al estudiar a los outsiders resulta importante atender a las tipologías existentes en el campo de la teoría política, como la propuesta por Rodríguez Andrés (2016), quien identifica un amplio repertorio de campos de procedencia, como ser el mundo del espectáculo (cantantes, actores, comediantes, presentadores de televisión) y del deporte. Además, el autor señala a aquellas personas que, sin ser particularmente sobresalientes en la «civilización del espectáculo» (Vargas Llosa, 2012), pero sí reconocidos en sus profesiones, deciden dar el salto a la política. En palabras de Rodríguez Andrés (2016), este grupo incluiría a «todos aquellos profesionales que, gozando de prestigio en su profesión de origen y, por tanto, siendo vistos como un modelo en la sociedad, deciden dar el salto a la política y de los que se espera que apliquen en ella el buen hacer que han mostrado en el ejercicio de sus respectivas profesiones» (p. 81). Comprendería a empresarios, jueces, economistas, periodistas, intelectuales, militares y activistas sociales, entre otras profesiones.

Como veremos en la próxima sección, Uruguay no ha tenido aún ejemplos de outsiders provenientes del mundo del espectáculo: los cuatro casos a analizar pertenecen al grupo de profesionales «tradicionales» que, sin ser particularmente conocidos o populares a partir de logros en el mundo del espectáculo o del deporte, deciden incursionar en política. Como se argumentará, serán precisamente esas pertenencias extrapolíticas las que permitirán a estos nuevos candidatos posicionarse dentro 
del campo político uruguayo de manera diferencial, constituyendo así sus perfiles políticos en términos narrativos.

\section{Los outsiders en la política uruguaya}

Esta sección estudia desde una perspectiva semiótico-narrativa el posicionamiento de cuatro outsiders que recientemente han irrumpido en el escenario político uruguayo: Ernesto Talvi, quien compitió en las elecciones internas de 2019 como candidato por el Partido Colorado (uno de los dos partidos fundacionales del Uruguay independiente), Juan Sartori, quien hizo lo mismo que Talvi, pero por el Partido Nacional (el otro partido fundacional), Guido Manini Ríos, quien compitió por el nuevo partido Cabildo Abierto, fundado a fines de 2018, y Edgardo Novick, cuya aparición en la política uruguaya con el Partido de la Gente por él creado data de mediados de la década de 2010. Los cuatro personajes resultan de interés dado que, a pesar de sus diferencias específicas, presentan algunos aspectos en común. El principal de ellos es que cada uno buscó ocupar un espacio en la esfera política que aún no estaba siendo ocupado por ningún otro candidato. El modo de lograrlo fue a partir del uso de su trayectoria personal, con un fuerte anclaje en la actividad prepolítica. En la presentación y discusión de cada candidato se atenderá a los siguientes aspectos: su afiliación o no a partidos existentes, su procedencia profesional, su discurso de llegada a la política y su posicionamiento narrativo.

\section{Ernesto Talvi: el académico}

Ernesto Talvi apareció en el campo político uruguayo en el año 2018 asociado al Partido Colorado, uno de los partidos fundacionales del Uruguay que, a comienzos del siglo XXI, se vio reducido electoralmente de manera significativa. Al elegir ingresar a la actividad política incorporándose a una fuerza política ya existente, Talvi es un outsider por provenir de un campo ajeno al político aunque no incursiona como alguien que está al margen de sus convenciones: según ha repetido en varias ocasiones, su admiración por las ideas batllistas (asociadas a José Batlle y Ordóñez, dos veces presidente del Uruguay a comienzos del siglo XX) fueron su gran motivación. De hecho, Talvi ha declarado en reiteradas ocasiones ser un «liberal progresista», defensor de la democracia y de las 
instituciones que dan forma al Estado de Derecho. Como afirmaba el candidato en una entrevista de 2018: «me considero un liberal, progresista e internacionalista. Y creo que esos fundamentos filosóficos retrotraen a los valores del primer batllismo. Pero el batllismo es una parte importante del Partido Colorado, así que me siento ambas cosas: colorado y batllista». ${ }^{8}$

Estas declaraciones dejan en deja en evidencia una estrategia narrativa de incorporación identitaria: la identidad del candidato como individuo se define a partir de sus identificaciones, que en este caso remiten a dos contenidos clásicos dentro del campo político uruguayo. Sin embargo, al crear su propio sector dentro del partido -al que llamó «Ciudadanos»-, Talvi tomó cierta distancia respecto al funcionamiento de estas definiciones tal como están articuladas de manera hegemónica en el Partido Colorado, dominado por figuras que están en política desde hace décadas, como el dos veces expresidente Julio María Sanguinetti, una figura a la que se asocia con una «vieja forma» de hacer política, caracterizada (en el imaginario social) por el clientelismo y el otorgamiento de cargos a allegados en organismos públicos. Como forma de marcar su especificidad, en 2018 Talvi afirmaba que «vamos a terminar con los directorios integrados por políticos vía premio consuelo a quienes no fueron electos. Prometo terminar con las empresas públicas como un aparato político clientelar para mantenerse en el poder». ${ }^{9}$

Antes de su incursión en política, Talvi era conocido en la esfera pública por dirigir CERES (Centro de Estudios de la Realidad Económica y Social), un think tank interesado principalmente por cuestiones económicas y sociales. Antes de volverse un candidato, Talvi fue ante todo un académico: un economista, un investigador no residente en una prestigiosa institución estadounidense, un doctor en Economía (nada menos que por la Universidad de Chicago), asesor en cuestiones macroeconómicas del Banco Interamericano de Desarrollo, etc. En síntesis: se trata de un personaje ya conocido en la esfera pública uruguaya que, a partir de su experiencia profesional previa, decide dar un salto a la política y que, al hacerlo, elige asociarse a uno de los partidos existentes, posicionándose fuertemente a partir de su perfil prepolítico: el del académico.

\footnotetext{
${ }^{8}$ https://www.montevideo.com.uy/Noticias/Talvi-en-Sere-Curioso-No-soy-politico-nivoy-a-serlo-pero-llegamos-para-quedarnos-uc703293

${ }^{9}$ https://www.montevideo.com.uy/Noticias/Talvi-en-Sere-Curioso-No-soy-politico-nivoy-a-serlo-pero-llegamos-para-quedarnos—uc703293
} 
$\mathrm{Al}$ incursionar en política, Talvi manejó un discurso en el que constantemente enfatizó su rol de outsider, como, por ejemplo, cuando en una entrevista de 2018 afirmó que «Ciudadanos es un proyecto nuevo y yo soy un candidato nuevo. No soy político, ni voy a serlo. Soy una persona que se ha pasado su vida en el diseño de políticas de gobierno, pero que vengo a hacer política». ${ }^{10} \mathrm{El}$ carácter de outsider, en este caso, tiene ciertas connotaciones de renovación que son precisamente las que permiten al candidato posicionarse como un héroe en la trama política, uno que viene a hacerse cargo de una situación que, según su apreciación, no es la ideal. La capacidad de llevar a cabo su plan de acción heroico se apoya en su experiencia previa, esto es, en su perfil académico. Como argumenta Musto Crucci (2020), la irrupción de Talvi en política «no ha sido para cambiar el sistema, sino que, como académico, volcar su conocimiento y su experiencia para mejorar el país según sus convicciones» (p. 231).

La afirmación de su condición de outsider es evidente también en un resonado intercambio de mayo de 2019 con Oscar Andrade en Twitter, en ese entonces precandidato presidencial por el Frente Amplio (Figura 1): la estrategia discursiva subyacente a su respuesta parecería ser que el hecho de ser un personaje nuevo en política lo inmuniza de las acusaciones y atribuciones que se le hacen al partido con el que se identifica. En síntesis: la relación entre el actor individual y el colectivo permite desarrollar estrategias discursivas de distinto alcance, algunas de las cuales pueden ser favorables para el posicionamiento del candidato, mientras que otras, no.

\footnotetext{
${ }^{10}$ https://www.montevideo.com.uy/Noticias/Talvi-en-Sere-Curioso-No-soy-politico-nivoy-a-serlo-pero-llegamos-para-quedarnos-uc703293
} 
Figura 1. Intercambio en Twitter entre Ernesto Talvi y Oscar Andrade

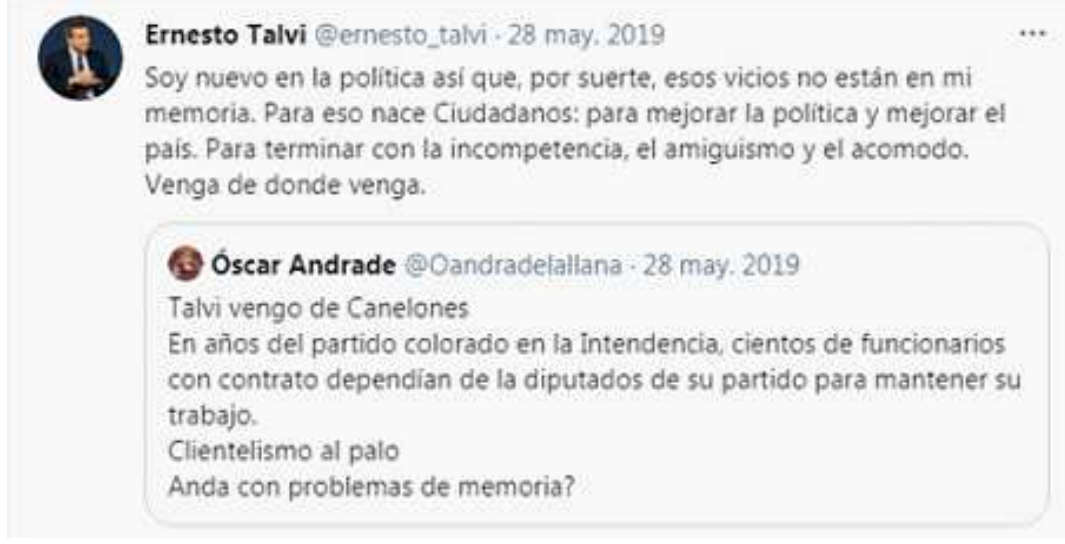

Fuente: Twitter

En las elecciones internas de junio, Talvi fue electo como único representante del Partido Colorado para las elecciones nacionales de octubre, en las que obtuvo un $12 \%$ de los votos y fue electo senador de la República. Para la segunda vuelta de las elecciones nacionales (instancia electoral en la que participan los dos candidatos más votados en octubre) apoyó a Luis Lacalle Pou, candidato por el Partido Nacional, quien finalmente fue electo presidente y que, al asumir la presidencia en marzo de 2020, lo designó como ministro de Relaciones Exteriores, función que ejerció hasta que, a mediados de 2020 , sorpresivamente renunció y se retiró de la política. ${ }^{11}$

\section{Juan Sartori: el empresario}

A diferencia del caso de Talvi, que era conocido en la esfera pública uruguaya debido a su actividad al frente de CERES, el empresario Juan Sartori no era conocido por el electorado uruguayo, ya que nunca tuvo participación activa en el país más allá de algún emprendimiento económico. Por eso, la sorpresa fue significativa cuando apareció en la escena política y anunció su postulación como candidato presidencial por el Partido Nacional, el otro partido fundacional del Uruguay junto al Colora-

\footnotetext{
${ }^{11}$ https://www.elpais.com.uy/informacion/politica/talvi-renuncio-banca-senado-actividadpolitica.html
} 
do. Como afirma Musto Crucci (2020), la de Sartori fue una irrupción «inesperada, sorpresiva y disruptiva» (p. 232): el candidato no solo no tenía ningún tipo de experiencia previa en política, sino que en diversas ocasiones se le cuestionó su conocimiento de la realidad socioeconómica uruguaya, dado que su familia emigró a Europa cuando él era un niño, nunca residió en el Uruguay, se formó profesionalmente en Suiza, está casado con una ciudadana rusa (hija de un magnate de aquel país) y la primera vez que votó en las elecciones nacionales fue, precisamente, en 2019. ${ }^{12}$

A diferencia de lo que sucedió con Talvi, que ya era parcialmente conocido, Sartori tuvo que presentarse ante la sociedad uruguaya, además de justificar su adhesión al Partido Nacional: hubo, por lo tanto, una estrategia de presentación personal y una de identificación con una identidad colectiva ya existente. No llama la atención que una de las primeras acciones de comunicación desarrolladas en el marco de su candidatura haya sido la campaña «iQuién es Juan Sartori??, que buscaba asociar un nombre a un individuo (mecanismo básico de la identificación personal) (Figura 2). El hecho de asociarse a uno de los dos partidos tradicionales del Uruguay demuestra cómo el candidato no surge como un rupturista, sino que busca aportar desde su experiencia al sistema político tal como es.

Figura 2: Posteo de Juan Sartori en Twitter

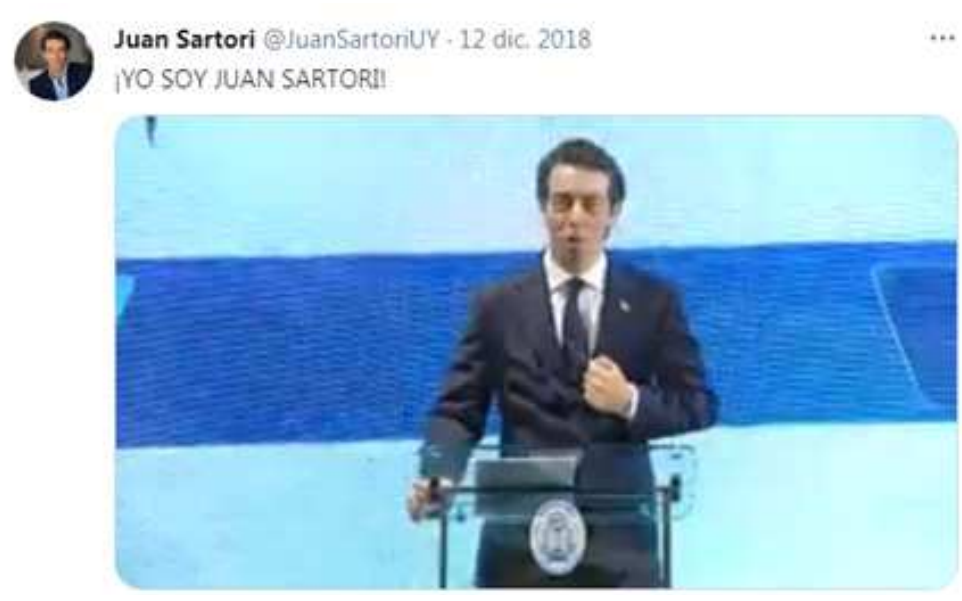

Fuente: Twitter

\footnotetext{
${ }^{12}$ https://www.elobservador.com.uy/nota/sartori-fue-a-una-entrevista-y-no-supo-responder-cuanto-es-el-desempleo-ni-el-salario-minimo-201932182746
} 
Al incursionar en política, también Sartori se apoyó fuertemente en su exitosa trayectoria como empresario para forjar su posicionamiento como candidato: como propone Musto Crucci (2020), Sartori «se posicionaba en su éxito como empresario para trasladarlo a la gestión pública» (p. 233). El éxito en la actividad prepolítica parecería ser lo que, al menos en términos narrativos, justifica la incursión en el campo. En ese movimiento hay también un gesto con ciertas tonalidades cercanas al arquetipo del héroe: teniendo sus necesidades (en este caso, económicas) más que cubiertas gracias a su actividad empresarial y financiera, el candidato regresa a su tierra de origen para mejorar las cosas.

Con un discurso por momentos extremadamente simplista y con el fuerte apoyo de operadores estratégicos en el campo de la comunicación (incluso hubo maniobras de campaña sucia), Sartori construyó una serie de mantras atractivos -como la propuesta de crear 100.000 puestos de trabajo u otorgar medicamentos gratis a los jubilados- que recuerdan a la incursión en política de Donald Trump, quien también se asoció a un partido tradicional y se posicionó en su rol de empresario exitoso. ${ }^{13}$ En las elecciones internas, Sartori obtuvo un $20,7 \%$ de los votos dentro del Partido Nacional, por lo que perdió la contienda frente a Luis Lacalle Pou, quien luego fue electo presidente de la República. Sin embargo, Sartori quedó en segundo lugar, por encima de figuras de larga trayectoria dentro del Partido, como Jorge Larrañaga. En las elecciones nacionales, Sartori fue electo senador.

\section{Guido Manini Ríos: el militar}

En su estudio sobre los outsiders, Rodríguez Andrés (2016) afirma que «a lo largo de la historia, muchos miembros de las Fuerzas Armadas han decidido dar el salto a la política presentándose a elecciones» (p. 87). El caso de Guido Manini Ríos es un ejemplo claro de esta situación, ya que el candidato decidió incursionar en la política luego de haber sido comandante en jefe de las Fuerzas Armadas desde 2015, cargo del que fue cesado en marzo de 2019 por Tabaré Vázquez, el entonces presidente de la República. Si bien Manini Ríos era conocido en la esfera pública por su cargo al mando del ejército nacional, su salto a la política fue, como señala Musto Crucci (2020), inesperado, meteórico y controvertido.

${ }^{13}$ https://www.elpais.com.uy/informacion/politica/juan-sartori-pregunta-respuestas.html 
Si se tiene en cuenta su discurso conservador, Manini Ríos podría haber ingresado a la política a través de la asociación con alguno de los dos partidos tradicionales (dentro de los que ciertamente hay sectores fuertemente conservadores). Sin embargo, el candidato eligió afiliarse a una nueva fuerza política, Cabildo Abierto, surgida a comienzos de 2019 de la mano de un grupo de ciudadanos con un significativo componente de militares retirados. A diferencia de los casos de Talvi y Sartori, que se focalizaron en presentarse a sí mismos y en justificar su ingreso a la política mediante la adhesión a partidos ya existentes, Manini Ríos debió concentrarse en presentar a su partido, esto es, a la identidad colectiva a la que representaba, ya que él era conocido por su experiencia militar. Por lo tanto, durante la campaña de 2019, el candidato (actor individual) y el partido (actor colectivo) establecieron una sinergia discursiva en la que uno servía como insumo para otorgar sentido al otro, según una lógica de equivalencia entre lo que propone Manini Ríos y lo que defiende el partido. ${ }^{14}$

En su ingreso al escenario político, Manini Ríos manejó un discurso crítico con el gobierno del Frente Amplio (al mando del poder Ejecutivo desde 2005), conservador y reformista, orientado a recuperar determinados valores perdidos que, discursivamente, el partido asocia con los orígenes históricos de la República Oriental del Uruguay y, concretamente, en el prócer José Gervasio Artigas y el artiguismo en torno a él construido (Figuras 3 y 4 ). ${ }^{15}$

Figura 3: Texto del partido Cabildo Abierto

GADA UNA DE NUESTRAS PROPUESTAS ESTA FUNDADAEN LA.

TRANSPARENCIA Y HONESTIDAD, PILARES FUNDAMENTALES PARA

RETOMAR LOS VALORES QUE DE AL.GUNA MANERA U OTRA LOS

URUGUAYOS HEMOS PERDIDO Y QUEREMOS RECUPERAR

Fuente: www.manini.uy

\footnotetext{
${ }^{14}$ Para un estudio discursivo sobre la identidad propuesta por el partido Cabildo Abierto, ver Moreno Barreneche (2021).

${ }^{15}$ https://ladiaria.com.uy/politica/articulo/2019/6/manini-rios-no-somos-derecha-ni-izquierda-ni-un-partido-militar-somos-artiguistas/
} 
Figura 4: Tweet de Guido Manini Ríos

\section{Gral. Guido Manini @GuidoManiniRios - 28 feb.}

Hace 210 años, a orillas del arroyo Asencio, los orientales iniciaban la revolución que, después de mucha sangre y sacrificio, nos llevó a la independencia.

Nuestro homenaje a aquellos patriotas, $y$ a quien poco después asumiria la conducción del movimiento, el Gral Artigas...

\section{Fuente: Twitter}

Musto Crucci (2020) sostiene que Manini Ríos «bregaba por recuperar los valores tradicionales que modelaron la patria, como la honestidad, la dignidad, la cultura del trabajo, la familia» (p. 235). Es decir, en su discurso había un componente reformista, consistente en recuperar cierto estado de cosas pasado, considerado como perdido. El candidato entraría así a desempeñar el papel del héroe, fundamentado por el hecho de ser un militar, con un compromiso patriótico con el Uruguay y con su prócer (Artigas).

En las elecciones nacionales de octubre, Manini Ríos obtuvo un sorpresivo $11 \%$ del total de los votos. Para la segunda ronda de noviembre, apoyó la candidatura de Luis Lacalle Pou, durante cuyo mandato ofició como senador y líder político del partido Cabildo Abierto.

Edgardo Novick: el laburante

Se podría afirmar que, con su incursión en política a mediados de la década del 2010, Edgardo Novick fue el primer outsider uruguayo en el sentido que se le da concepto en la teoría política actual. El candidato irrumpió en el escenario político en 2015 de cara a las elecciones municipales de mayo, en las que fue candidato por el Partido de la Concertación, una coalición instrumental establecida por los partidos Colorado y Nacional para disputarle la intendencia de Montevideo al Frente Amplio. En dichas elecciones, Novick fue el segundo candidato más votado, por lo que no accedió al cargo. En 2016 fundó el Partido de la Gente para continuar con su carrera en política. En 2019 se presentó como candidato a las elecciones nacionales de octubre, en las que obtuvo un bajísimo resultado. 
De los cuatro casos aquí estudiados, el de Novick es quizá el más interesante en términos semióticos, ya que gran parte de su posicionamiento en la esfera política estuvo apoyada en su proceso de transformación previo a ser candidato. Novick proviene de una familia de trabajadores y, según ha declarado en diferentes oportunidades, desde sus 14 años ha debido trabajar (por ejemplo, como feriante). ${ }^{16}$ Actualmente, es un reconocido y exitoso empresario de los ámbitos de la vestimenta, gastronómico y de superficies comerciales. Sin embargo, su posicionamiento en política no se construyó a partir de su condición de empresario exitoso (como en el caso de Juan Sartori), sino principalmente a partir de su apego a una cultura del trabajo. En términos narrativos, fue esta la que le permitió recorrer su camino heroico hasta llegar al éxito, por lo que ahora dicho camino seguirá en el terreno político. Como se aprecia en las categorías empleadas para referir a los cuatro candidatos analizados, la de «laburante» es la única que no refiere a una profesión, sino más bien a una actitud.

De hecho, como se ve en las Figuras 5 y 6, el tema del respeto por el trabajo fue un pilar constante del discurso de Novick. Por eso, antes que como empresario, su rol temático en el ámbito político se apoyó en ser un laburante, una expresión coloquial para designar a quien tiene una fuerte ética del trabajo y que, gracias a ella, puede salir adelante.

Figura 5: Tweet de Edgardo Novick

\section{Edgardo Novick @EdgardoNovick.7 sept. 2019}

TRABAJO

Recuperaremos la cultura del trabajo y el esfuerzo como camino principal para la superación personal y una vida digna.

¡HAY EQUIPO, HAY PROPUESTAS!

Fuente: Twitter

\footnotetext{
${ }^{16}$ https://www.elpais.com.uy/informacion/edgardo-novick-feriante-empresariointendencia.html
} 
Figura 6: Tweet de Edgardo Novick

\section{Edgardo Novick @EdgardoNovick.1 may.2015}

Feliz dia a todos los trabajadores. A aquellos que tienen un sueño por el que luchan dia a dia.

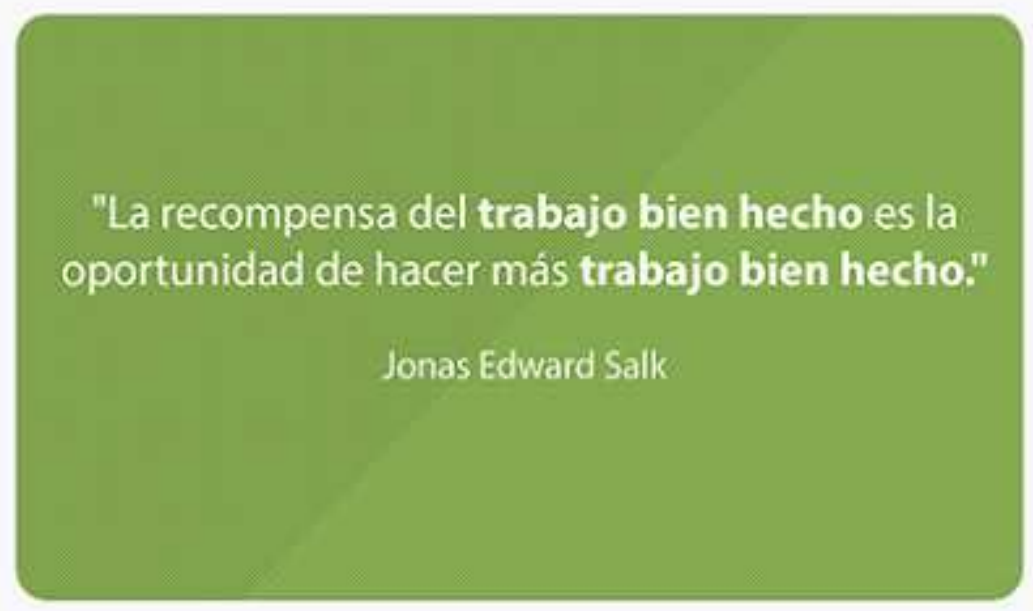

Fuente: Twitter

Sin embargo, a pesar de la prominencia de dicho componente de carácter más bien ético y actitudinal, el posicionamiento de Novick no dejó de lado otros aspectos vinculados con un saber hacer profesional y específico, como el de las capacidades de administración y de gestión empresarial. En el caso de este candidato, sus características personales parecen pesar más que en el caso de los otros tres outsiders aquí considerados, cuya legitimidad se apoya sustancialmente, al menos en términos discursivos, en sus profesiones.

\section{Conclusiones}

El objetivo de este artículo fue examinar desde un abordaje semiótico el reciente fenómeno del ingreso a la escena política uruguaya de cuatro candidatos outsiders. Por ello, debería leerse como complementario al análisis politológico realizado por Musto Crucci (2020) en su artículo «El ingreso de políticos outsiders a la partidocracia uruguaya». A su 
vez, el estudio de caso debería funcionar como una contribución más a una línea de investigación de la política uruguaya desde una perspectiva semiótica, hasta el momento inexistente y que recientemente he intentado explorar (Moreno Barreneche, 2020d).

Como vimos, los cuatro outsiders estudiados en estas páginas presentan un parámetro en común: su ingreso al campo político se vio acompañado de una serie de estrategias y lógicas discursivas orientadas a delimitar un espacio propio en el entramado político para llevar a cabo su construcción actorial. Estas estuvieron fuertemente apoyadas en hechos tangibles, vinculados con la biografía de los candidatos: concretamente, con sus posicionamientos dentro de los campos profesionales de los que provenían. Así, Ernesto Talvi fue ante todo un académico (un economista) que no se convertiría en «un político», Sartori fue un exitoso empresario que logró su fortuna fuera del Uruguay y que regresa a su país para modernizarlo, Manini Ríos fue un militar que incursiona en política para poner orden y restaurar ciertos valores perdidos y Novick fue un empresario, pero ante todo un trabajador, un laburante, que se hizo de abajo y que intentó forjar en el país una cultura del trabajo. Claramente, en estas caracterizaciones se puede apreciar cómo la realidad social, de naturaleza intersubjetiva, discursiva y relacional, es filtrada por ciertos mecanismos de naturaleza narrativa que son de sumo interés para la semiótica.

\section{Referencias bibliográficas}

Arfuch, L. (Ed.). (2005). Identidades, sujetos, subjetividades. Buenos Aires, Argentina: Prometeo.

Barr, R. (2009). Populists, Outsiders and Anti-Establishment Politics. Party Politics, 15(1), 29-48.

Carreras, M. (2013). Presidentes outsiders y ministros neófitos: un análisis a través del ejemplo de Fujimori. América Latina hoy, (64), 95-118.

Casullo, M. E. (2019). ¿Por qué funciona el populismo? Buenos Aires, Argentina: Siglo XXI.

Cerna Villagra, S. (2012). La senda del outsider: factores que explican la emergencia de candidatos exógenos al sistema de partidos en Perú y Paraguay. Estudios Paraguayos, XXIX y XXX (1 y 2), 117145 . 
Eco, U. (1976). Tratado de semiótica general. Barcelona, España: Lumen.

Fabbri, P. (1998). El giro semiótico. Barcelona, España: Gedisa.

Goffman, E. (1959). La presentación de la persona en la vida cotidiana. Buenos Aires, Argentina: Amorrortu.

Hjelmslev, L. (1943). Prolegomena to a Theory of Language. Madison, Estado Unidos: Wisconsin University Press.

Laclau, E. (2005). La razón populista. Buenos Aires, Argentina: Fondo de Cultura Económica.

Landowski, E. (2014). Sociossemiótica: uma teoria geral do sentido. Galáxia, (27) 10-20.

Lotman, J. (1996). La semiosfera, I. Madrid, España: Cátedra.

Mouffe, C. (2007). En torno a lo político. México, México: Fondo de Cultura Económica.

Moreno Barreneche, S. (2020a). Sentido, relaciones e interacciones. Intersecciones entre el pensamiento relacional y la sociosemiótica. Andamios, (44), 15-37.

Moreno Barreneche, S. (2020b). Mind the Gap! On the Discursive Construction of Collective Political Identities. Punctum, 6(2), 11-27.

Moreno Barreneche, S. (2020c). Polarización política y fanatismo 'blando': una hipótesis semiótica». DeSignis, (33), 143-158.

Moreno Barreneche, S. (2020d). Polarización política en Uruguay: el neoliberalismo como categoría de sentido en la articulación de las identidades colectivas. Sociedad, (40), 104-117.

Moreno Barreneche, S. (2021). Artiguismo, restauración y usos estratégicos del pasado. La construcción discursiva de la identidad colectiva asociada al partido Cabildo Abierto. Cuadernos del CLAEH, 40 (113), 11-34.

Musto Crucci, F. (2020). El ingreso de políticos outsiders a la partidocracia uruguaya. Cuadernos del Centro de Estudios en Diseño y Comunicación, (112), 225-240.

Paolucci, C. (2012). Sens et cognition: La narrativité entre sémiotique et sciences cognitive. Signata, (3), 299-316.

Paolucci, C. (2021). Cognitive Semiotics. Integrating Signs, Mind, Meaning and Cognition. Nueva York, Estados Unidos: Springer. 
Paschalidis, G. (2020). Introduction. Politics as a Communicative Project. Punctum, 6 (2), 5-9.

Peñamarín, C. (2020). Fronteras afectivas de la esfera pública y semiótica pragmática. CIC. Cuadernos de Información y Comunicación, (25), 61-75

Rodríguez Andrés, R. (2016). El ascenso de los candidatos outsiders como consecuencia de las nuevas formas de Comunicación Política y la desafección ciudadana. Comunicación y Hombre, (12), 73-95.

Vargas Llosa, M. (2012). La civilización del espectáculo. Montevideo, Uruguay: Alfaguara.

Verón, E. (1987). La palabra adversativa. Observaciones sobre la enunciación política. En Verón, E. et al (Eds.). El discurso político. Lenguajes y acontecimientos. Buenos Aires, Argentina: Hachette.

Verón, E. (1988). La semiosis social. Barcelona, España: Gedisa.

Verón, E. (1989). Semiótica y teoría de la democracia. Revista de Occidente, (92), 130-142.

Verón, E. (1994). Mediatización, comunicación política y mutaciones de la democracia. Semiósfera, (2), 5-36.

Verón, E. (1998). Mediatización de lo político. Estrategias, actores y construcción de los colectivos. En Gauthier, G., Gosselin, A. y Mouchon, J. (Comps.). Comunicación y politica. Barcelona, España: Gedisa. 